\title{
Ethmoidal Sinusitis
}

National Cancer Institute

\section{Source}

National Cancer Institute. Ethmoidal Sinusitis. NCI Thesaurus. Code C34597.

An acute or chronic inflammatory process affecting the mucous membrane of the ethmoid sinus. 